\title{
DRAFT
}

\section{Use of Heritage Hardware on Orion MPCV Exploration Flight Test One}

\author{
George Edward Rains ${ }^{1}$ \\ Jacobs Engineering, Houston, Texas, 77058 \\ and \\ Cynthia D. Cross ${ }^{2}$ \\ NASA Johnson Space Center, Houston, Texas, 77058
}

\begin{abstract}
Due to an aggressive schedule for the first space flight of an unmanned Orion capsule, currently known as Exploration Flight Test One (EFT1), combined with severe programmatic funding constraints, an effort was made within the Orion Program to identify "heritage hardware," i.e., already existing, flight-certified components from previous manned space programs, which might be available for use on EFT1. With the end of the Space Shuttle Program, no current means exists to launch MultiPurpose Logistics Modules (MPLMs) to the International Space Station (ISS), and so the inventory of many flight-certified Shuttle and MPLM components are available for other purposes. Two of these items are the MPLM cabin Positive Pressure Relief Assembly (PPRA), and the Shuttle Ground Support Equipment Heat Exchanger (GSE HX). In preparation for the utilization of these components by the Orion Program, analyses and testing of the hardware were performed. The PPRA had to be analyzed to determine its susceptibility to pyrotechnic shock, and vibration testing had to be performed, since those environments are predicted to be more severe during an Orion mission than those the hardware was originally designed to accommodate. The GSE HX had to be tested for performance with the Orion thermal working fluids, which are different from those used by the Space Shuttle. This paper summarizes the activities required in order to utilize heritage hardware for EFT1.
\end{abstract}

\section{INTRODUCTION}

The long-range plans and schedules of the Orion Program have changed frequently since early 2010. Now known officially as the Orion Multi-Purpose Crew Vehicle (MPCV), the first flight into space of an Orion capsule is currently scheduled for late 2013. Referred to within the Orion Program as Exploration Flight Test One (EFT1), this mission is being planned as an unmanned, two-orbit flight which will demonstrate spacecraft power systems, communication and tracking, active and passive thermal control, and re-entry and landing systems. Orion Prime Contractor Lockheed Martin will be responsible for planning and conducting the EFT1 mission, with support and assistance from NASA.

Due to severe programmatic funding constraints, the Environmental Control and Life Support (ECLS) capabilities of the Orion EFT-1 spacecraft will be very limited. The only ECLS hardware currently planned for installation on the EFT-1 vehicle is minimal Active Thermal Control hardware, including cold plates, coolant loops, pumps, and an ammonia boiler necessary to reject heat from the avionics equipment, plus the positive and negative pressure relief valves needed to passively control the cabin air pressure.

\footnotetext{
${ }^{1}$ Orion ECLS Subsystem Manager, Pressure Control System, EC6/Crew and Thermal Systems Divison.

${ }^{2}$ Orion ECLS Subsystem Manager, Active Thermal Control System, EC6/Crew and Thermal Systems Divison
} 
In an effort to reduce the cost of even these limited ECLS components, an investigation was made within the Orion Program into the possible use of so-called "heritage hardware," i.e., already existing, flight-certified components from previous manned space programs, which might be available for use on EFT1, and even beyond. Several

components of "heritage hardware" were considered, but only two appeared to be able to meet EFT-1 requirements: the Positive Pressure Relief Assembly (PPRA) from the ISS Multi-Purpose Logistics Module (MPLM), and the Ground Support Equipment Heat Exchanger (GSE HX) from the recently concluded Space Shuttle Program. Both of these heritage hardware items are currently planned for use on EFT-1.

\section{POSITIVE PRESSURE RELIEF ASSEMBLY (PPRA)}

\section{Hardware Description}

The purpose of the Positive Pressure Relief Assembly (PPRA) is to automatically relieve atmospheric overpressure in the cabin (habitable volume) of the spacecraft, should that condition occur. The design of the MPLM PPRA is a very slight modification of the older Shuttle Positive Pressure Relief Valve (PPRV). (Note that the Space Shuttle and Orion Programs normally use the term PPRV for this piece of hardware, and for most purposes the terms PPRA and PPRV are interchangeable.) The basic performance characteristics of the MPLM PPRA are as follows:

- Crack pressure: $15.05-15.14$ psid

- Full open pressure: $\leq 15.42$ psid

- Reseat pressure: $\geq 14.82$ psid

- Maximum flow rate: 150 lbs gas/hour @ 15.42 psid

- Dimensions: approximately 8 inches x 7 inches x 5 inches

- Total assembly weight: 5.5 pounds (includes non-propulsive vent on the exterior of the cabin pressure shell)

There are two pressure-sealing surfaces inside the body of the valve. One is a spring-loaded poppet, which responds automatically and mechanically to the difference in atmospheric pressure between the inside and the outside of the cabin, and the other is a motorized butterfly valve with a manual override. The butterfly valve must be in the "open" position in order for gas to flow through the spring-loaded poppet, and thus out of the cabin through the valve, when the "crack" pressure is reached.

Figure 1 is a photograph of a Class III (non-flight certified) PPRA. 


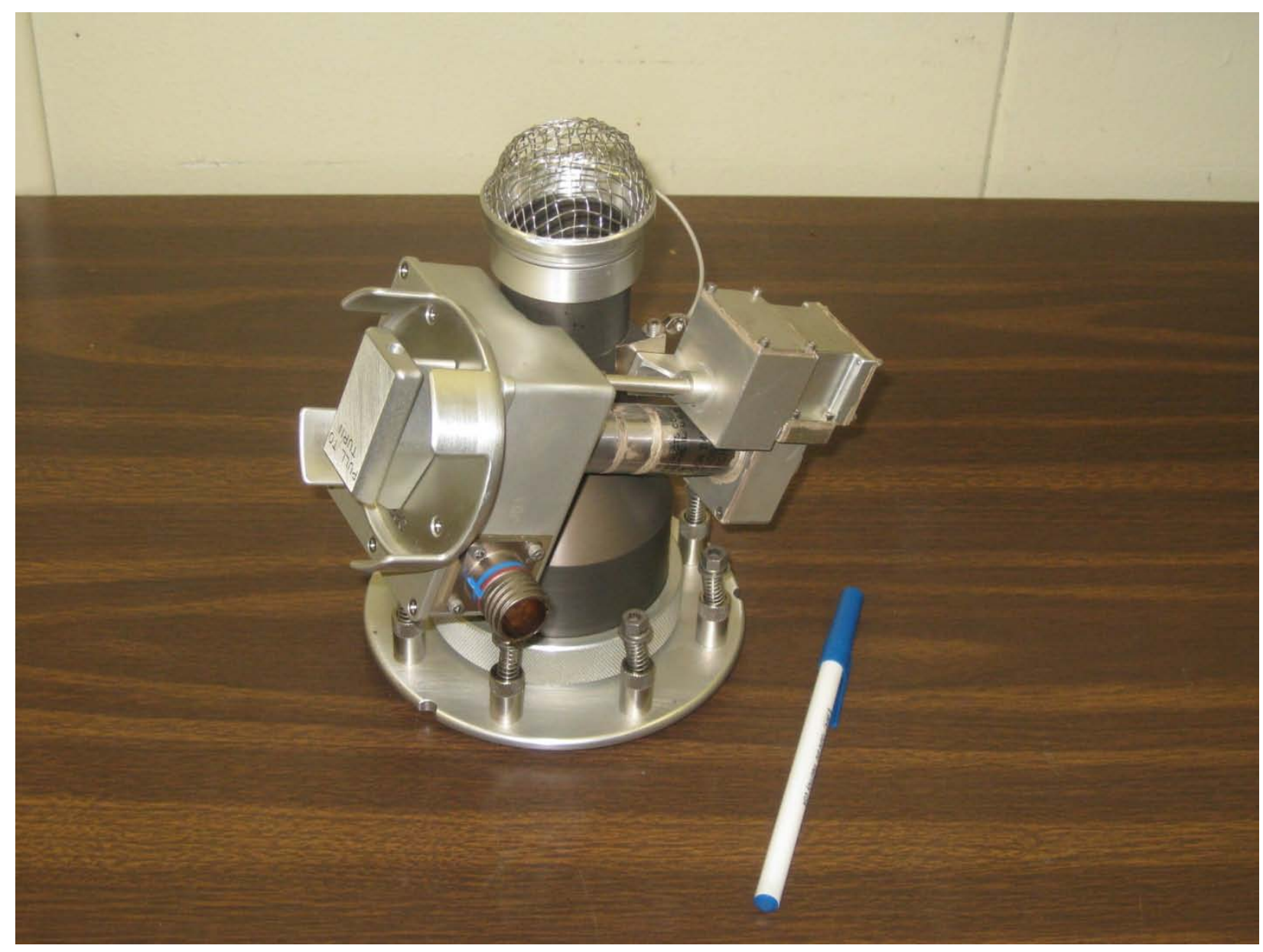

Figure 1. Class III (non-flight certified) PPRA. Note the standard-sized ball-point pen for scale.

\section{Positive Pressure Relief Requirements for Exploration Flight Test One}

As currently planned, a complete Orion spacecraft will include a newly-designed Orion PPRV with a flow rate of at least 800 lbs gas/hour @ 15.55 psid, which is approximately 5.3 times greater than the capability of the heritage MPLM PPRA. Two additional requirements for the Orion PPRV are that the "crack" pressure must be at least 15.15 psid, and that the valve be full open at a differential pressure of no greater than 15.55 psid. The minimum crack pressure of 15.15 psid is due to an interface requirement with the ISS, not from any inherent Orion rationale. For the EFT-1 mission, as long as the valve meets its leakage requirements, a specific minimum crack pressure is not needed. The requirement to be full open by 15.55 psid, on the other hand, is due to the maximum design pressure of the Orion crew module, which is 15.55 psid, and that is applicable to the EFT-1 mission.

The reason such a large flow rate, at least 800 lbs gas/hour @ 15.55 psid, is required is the presence of an inert gas fixed fire suppression system within the Orion avionics bays, which are located inside the pressurized volume of the spacecraft. The inert gas consists of approximately 7.9 lbs of nitrogen stored within a small dedicated gas tank, with an initial tank pressure of 5000 psi. When activated, the nitrogen in the tank is dumped into the avionics bays, which will quickly force most of the oxygen out of the partially-sealed bays and extinguish the fire. This action will cause the air pressure in the Orion cabin to increase by approximately 3 psi in less than two minutes. If the vehicle was in space, and the initial cabin pressure was the standard $14.7 \mathrm{psi}$, activating the fixed fire suppression system would cause the cabin to very rapidly exceed its maximum design pressure of 15.55 psid. This fire suppression strategy is therefore what drives the need for an Orion PPRV with a high mass flow rate. 
However, the fixed fire suppression system will not be installed on the EFT1 vehicle, which will also not have any gas tanks, pressure regulators, or any means of active cabin pressurization or pressure control. The only possible cause of cabin overpressurization during the EFT-1 mission would be a significant increase in the air temperature inside the cabin. In that event, the $150 \mathrm{lbs}$ / hour flow rate of the MPLM PPRA will be more than sufficient to relieve the overpressure.

\section{Random Launch Vibration}

The largest potential issues with the use of a heritage PPRA on the EFT-1 mission were the random vibration environment during an Orion launch and ascent, and pyrotechnic shock. The random vibration questions were easier to address, and so these were considered first.

The random vibrations experienced by spacecraft components during a Space Shuttle launch and ascent are somewhat different from those currently projected for an Orion launch and ascent. Figure 2 gives a comparison of the two environments. While the total (integrated) power level of the Shuttle vibration environment is slightly greater, the frequency content is different, and the Orion vibration levels are expected to be greater in the range of 30 to 500 Hertz.

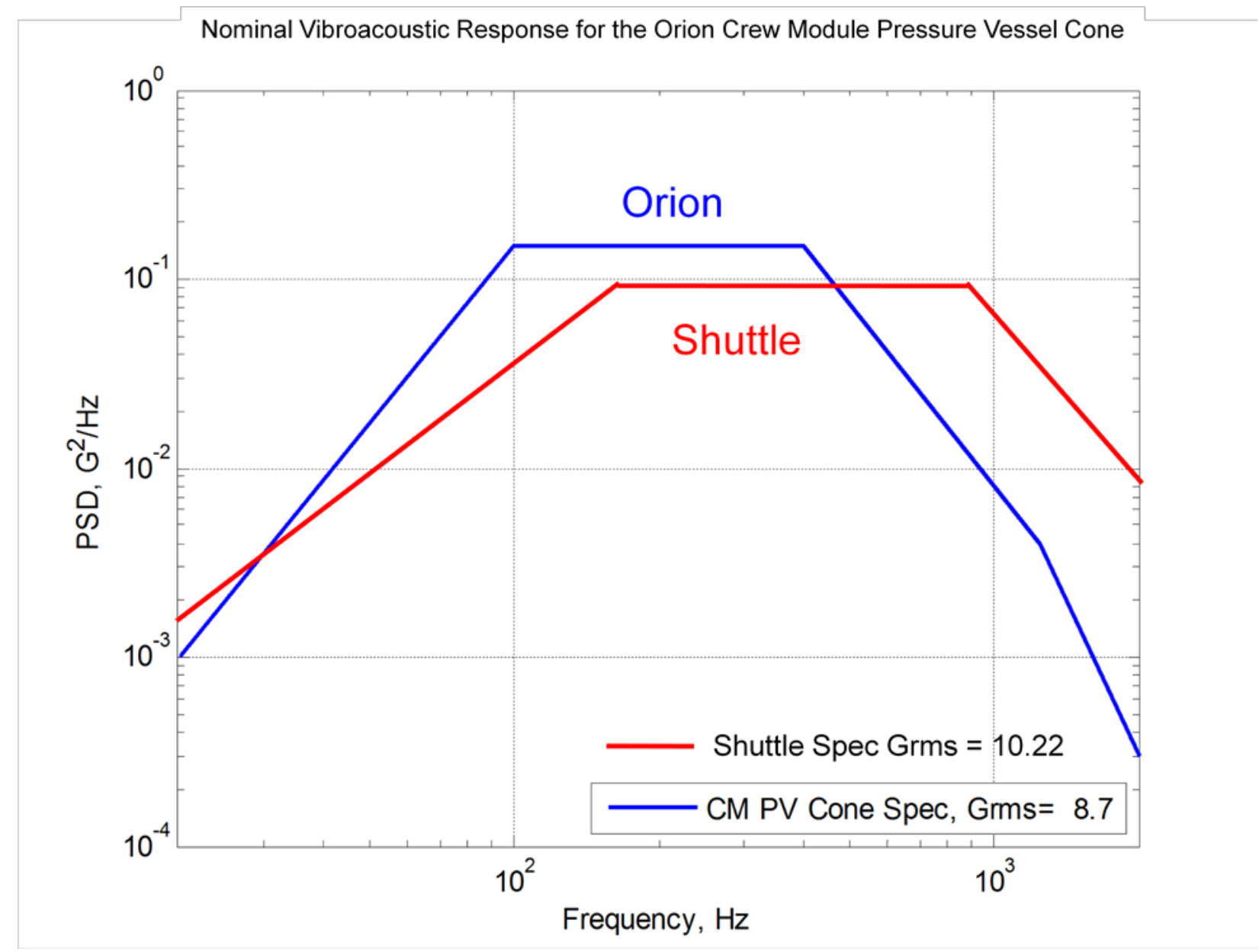

Figure 2. Orion and Shuttle Random Vibration Curves (Nominal Ascent)

It was quickly recognized that the most fragile and problematic components within the PPRA were the motor connected to the butterfly valve, and its electrical connections. The rest of the PPRA, including the spring-loaded poppet and its sealing surfaces, were obviously more robust. Because the fault tolerance requirements for the unmanned EFT-1 mission had already been relaxed relative to those for later manned flights, agreement was reached that the PPRA could remain unpowered and electrically unconnected during the EFT-1 mission, and this would meet the EFT-1 fault tolerance requirements. The manual override to the butterfly valve will be launched in the "open" position, and the electrical harness 
to provide power to the motor will not be installed. Any damage to the motor that might be incurred during the mission will therefore have no impact on the mechanical function and performance of the valve.

\section{Vibration Testing of Class III PPRA}

Although concerns about the motor and its electrical connections had been alleviated, sufficient uncertainties remained to justify a random vibration test. This was conducted at the Johnson Space Center, using a complete and functional Class III (non-flight certified) PPRA. The purposes of the test were to:

- Obtain data and provide confidence that a Class I (flight-certified) valve would survive and function in the Orion EFT-1 launch environment.

- Determine if either the nominal Orion launch vibration loads, or the $+3 \mathrm{~dB}$ levels specified by the Constellation Program Environmental Qualification and Acceptance Testing Requirements (CEQATR) for Protoflight hardware, "broke” the valve, or resulted in unacceptably high air leakage under vibration.

- Determine the approximate "crack" pressures before and after each axis of vibration.

- Quantify the amount of air leakage through the valve during each axis of vibration, because air leakage due to valve "chatter" during vibration was thought to be a potential issue.

It should be noted that the vibration test was not intended to be a formal qualification or certification test. The Class III valve tested was the only PPRA that was available at that time. It was functional, but it had been serving as a desk paperweight for 10 years. The pressure gauge used for the test was precise to $0.01 \mathrm{psi}$, but was not formally calibrated. And finally, the measurement of "crack pressure" during the test was subjective, determined by visual observation of the behavior of the pressure gauge.

Figure 3 lists the parameters used for the test. The first three runs, which vibrated the valve in the $\mathrm{x}, \mathrm{y}$, and $\mathrm{z}$ axes, respectively, used the input parameters shown on the left. These correspond to the "Orion" nominal ascent random vibration curve shown in Figure 2. The final three runs used the input parameters shown on the right. These correspond to the $+3 \mathrm{~dB}$ levels called for in the CEQATR document for Protoflight hardware (i.e., hardware components for which no test-dedicated qualification article exists, and all production hardware is intended for flight).

\begin{tabular}{|c|c|c|}
\hline \multicolumn{2}{|c|}{ CM PV Cone Spec } \\
\cline { 1 - 2 } Grms=8.7 \\
\cline { 1 - 2 } Freq $(\mathrm{Hz})$ & PSD $\left(\mathrm{g}^{\wedge} 2 / \mathrm{Hz}\right)$ & \multirow{2}{*}{ Tol $(\mathrm{dB})$} \\
\hline 20 & 0.001 & $+1.5,-1.5$ \\
\hline 100 & 0.15 & $+1.5,-1.5$ \\
\hline 400 & 0.15 & $+1.5,-1.5$ \\
\hline 1250 & 0.004 & $+3.0,-3.0$ \\
\hline 2000 & 0.0003 & $+3.0,-3.0$ \\
\hline
\end{tabular}

Nominal Ascent:

3 runs, one for each axis

Duration: 112 sec/axis

\begin{tabular}{|c|c|c|}
\hline \multicolumn{2}{|c|}{ CM PV Cone Spec } \\
\cline { 1 - 2 } Grms=12.3 \\
\cline { 1 - 2 } Freq (Hz) & PSD $\left(\mathrm{g}^{\wedge} 2 / \mathrm{Hz}\right)$ & \multirow{2}{*}{ Tol (dB) } \\
\hline 20 & 0.002 & $+1.5,-1.5$ \\
\hline 100 & 0.30 & $+1.5,-1.5$ \\
\hline 400 & 0.30 & $+1.5,-1.5$ \\
\hline 1250 & 0.008 & $+3.0,-3.0$ \\
\hline 2000 & 0.0006 & $+3.0,-3.0$ \\
\hline
\end{tabular}

+3dB Protoflight:

3 runs, one for each axis

Duration: 112 sec/axis

Figure 3. Test Parameters of the Random Vibration Test.

Figure 4 is a summary of the data obtained during the test. 


\begin{tabular}{l|c|c|r|}
\multicolumn{4}{c}{ Nominal Ascent } \\
Parameter & $\mathbf{Z}$ Axis (1 $\left.\mathbf{1}^{\text {st }}\right)$ & Y Axis $\left(\mathbf{2}^{\text {nd }}\right)$ & X Axis (3 $\left.{ }^{\text {rd }}\right)$ \\
\hline $\begin{array}{l}\text { Pre-Vibration Crack } \\
\text { Pressure }\end{array}$ & 15.70 psid & 15.68 psid & 15.70 psid \\
$\begin{array}{l}\text { Post-Vibration } \\
\text { Crack Pressure }\end{array}$ & 15.68 psid & 15.70 psid & 15.70 psid \\
$\begin{array}{l}\text { Air Leakage During } \\
\text { Vibration (lbs) }\end{array}$ & $0.0038 \mathrm{lbs}$ & 0 & 0
\end{tabular}

\begin{tabular}{|c|c|c|c|}
\hline \multicolumn{4}{|c|}{ + 3dB Protoflight } \\
\hline Parameter & Z Axis $\left(3^{\text {rd }}\right)$ & $Y$ Axis $\left(2^{\text {nd }}\right)$ & $X$ Axis (1 $\left.1^{\text {st }}\right)$ \\
\hline $\begin{array}{l}\text { Pre-Vibration Crack } \\
\text { Pressure }\end{array}$ & 15.69 psid & 15.70 psid & 15.70 psid \\
\hline $\begin{array}{l}\text { Post-Vibration } \\
\text { Crack Pressure }\end{array}$ & 15.68 psid & 15.69 psid & 15.70 psid \\
\hline $\begin{array}{l}\text { Air Leakage During } \\
\text { Vibration (Ibs) }\end{array}$ & $0.0084 \mathrm{lbs}$ & 0 & $1.36 \times 10^{-4} \mathrm{lbs}$ \\
\hline
\end{tabular}

Figure 4. Results of the Random Vibration Test on the Class III PPRA.

One interesting result was that the "chatter" effect (air leakage during vibration) turned out to be insignificant, and will not be an issue for the use of an identical Class I valve on the EFT-1 mission. Air leaks of the size recorded could not be measured, and would not be noticed, on an actual spacecraft. It was also clear that the nominal Orion and $+3 \mathrm{~dB}$ Protoflight vibration levels did not damage the mechanical function of the valve, or affect its performance in any significant way. The Class III PPRA had been uncontrolled for 10 years (was a desk paperweight), and yet performed reliably and repeatably. Pending the results of a pyrotechnic shock analysis (see below), an identical, properly-maintained Class I PPRA would obviously be acceptable for the EFT-1 mission.

\section{Hardware Availability}

After all other program needs were accounted for, as of early 2011 a total of five flight-certified MPLM PPRA's remained in the ISS / MPLM inventory at the Kennedy Space Center. Given the favorable results of the vibration test on the Class III PPRA, the Orion Program requested, and was granted, the loan of two spare Class I MPLM PPRA's from the ISS Program. One of these is intended to fly on the EFT-1 mission, and the other will serve as a spare.

\section{Pyrotechnic Shock}

The term "pyrotechnic shock" refers to very strong accelerations of very short duration and small displacement. On spacecraft, these types of accelerations are typically caused by deliberate pyrotechnic (i.e., explosive) events, such as the detonation of explosive bolts, the firing of parachute deployment mortars, etc. Pyrotechnic shock is normally an issue for smaller and more brittle components, such as electronics and small ceramic parts, especially those which are located in close proximity to the pyrotechnic hardware. The high frequency shock waves generated by these explosive events can readily break small and/or brittle components. Larger metallic parts and fittings, and components whose major modes of vibration (i.e., critical resonant frequencies) are $100 \mathrm{Hertz}$ or less, are typically not susceptible. Exposure to pyrotechnic shock can be mitigated through the use of shock absorbing materials and mountings, as well as physical separation (maximum possible distance) between the pyrotechnic hardware and susceptible components. 
Most Space Shuttle and MPLM components had no significant exposure to pyrotechnic shock events, and so were not deliberately designed to withstand these kinds of environments. However, the much smaller Orion spacecraft will experience multiple pyrotechnic shock events during every mission, two of which are significant for the PPRA: the jettison of the Launch Abort System (LAS) during ascent, and the jettison of the Forward Bay Cover (FBC) during atmospheric descent.

Tests involving pyrotechnic materials are complicated and expensive to conduct, and the Orion Program had no budget for performing pyrotechnic shock testing on the PPRA's being considered for use on the EFT-1 mission. It was clear that the large metallic body of the PPRA would not be susceptible to pyrotechnic shock, but considerable uncertainty existed regarding the smaller internal components.

In order to evaluate the susceptibility of the internal parts of the PPRA to pyrotechnic shock, a reasonably accurate mass had to be determined for the small moving parts inside the valve. Obtaining this data proved to be a challenge. Apart from high-level assembly drawings, the original engineering / manufacturer data were no longer available. The Class I flight units at KSC were not available for disassembly, and Orion personnel were reluctant to dismantle their functional Class III engineering unit, which had just successfully completed random vibration testing, and which might still be needed for additional tests. Based on the drawings that were available, the best that could be done was to estimate the total weight of the moving parts inside the PPRA at approximately 1.0 ounces, but with considerable uncertainty. More precision was needed for a meaningful analysis.

Fortunately, at this point an old Space Shuttle Class I (flight qualified) PPRV, apparently the original Shuttle engineering / qualification test unit, was discovered in the Bonded Storage Room of the Crew and Thermal Systems Division at the Johnson Space Center, where it had been located since 1982. This unit was downgraded to Class III, and then removed from bonded storage for disassembly and study. The weight of the moving parts inside was 1.35 ounces.

Armed with this information, a numerical analysis was then conducted to determine the susceptibility of the moving parts inside the PPRA to pyrotechnic shock. The result was a determination that the fundamental frequencies of vibration in the direction of poppet spring motion (the $\mathrm{Z}$ axis during the random vibration test) were all 100 Hertz or less. This was good news, since it meant (1) that the moving parts inside the body of the PPRA were probably not susceptible to pyrotechnic shock, and (2) that the already-completed random vibration test probably induced a more severe response on the hardware than the Orion pyrotechnic shock events in question. Given these results, both NASA and Lockheed Martin shock experts were in agreement that the PPRA would not be susceptible to pyrotechnic shock, and that a shock qualification for the PPRA would not be required.

\section{Certification Issues and More Vibration Testing}

While assembling the paperwork for the loan of two Class I PPRA's from the ISS Program to Orion, and in preparing a Government Furnished Equipment (GFE) directive under which NASA would then provide the PPRA's to Orion Prime Contractor Lockheed Martin for use on EFT-1, it was discovered that the Class III unit used for the vibration test was labeled with a different part number than the Class I flight units. This was apparently due to the fact that the Class III unit had technically been procured for the X-38 Program, while the Class I units had been procured for the MPLM Program. Although the Class III unit was visually and dimensionally identical to the Class I units, and was obviously the same design, no paperwork or documentation could be found covering the Class III unit. Lockheed Martin personnel and the NASA Orion Safety representative both felt, in view of the different part numbers and the lack of any surviving paperwork for the Class III unit, that the vibration test would have to be repeated with a Class I unit, in order to establish a sufficient level of confidence in the hardware.

The already-approved transfer of two Class I PPRA's from the ISS MPLM inventory to Orion was therefore accelerated, and one of these units was shipped to JSC for a repeat of the random vibration test that had previously been conducted. This second round of vibration testing utilized the same test setup, test procedures, test parameters, instrumentation, vibration spectra, power levels, and durations as the previous random vibration test of the Class III unit (see Figures 2 and 3 above). As with the first vibration test, it should be noted that the test was not intended to be a formal qualification or certification test. The purpose of the test was to obtain data, and to provide confidence that the valve would survive and function in the Orion EFT-1 launch environment. 
Nominal Ascent

\begin{tabular}{l|c|c|c|}
\hline Parameter & $\mathbf{Z}$ Axis $\left.\mathbf{( 3}^{\text {rd }}\right)$ & Y Axis $\left.\mathbf{( 2}^{\text {nd }}\right)$ & X Axis $\left.\mathbf{( 1}^{\text {st }}\right)$ \\
\hline $\begin{array}{l}\text { Pre-Vibration Crack } \\
\text { Pressure }\end{array}$ & 15.11 psid & 15.10 psid & 15.01 psid \\
$\begin{array}{l}\text { Post-Vibration } \\
\text { Crack Pressure }\end{array}$ & 15.02 psid & 15.11 psid & 15.10 psid \\
$\begin{array}{l}\text { Air Leakage During } \\
\text { Vibration (lbs) }\end{array}$ & 0.0022 lbs & 0 & 0
\end{tabular}

$+3 \mathrm{~dB}$ Protoflight

\begin{tabular}{|c|c|c|c|}
\hline Parameter & Z Axis (1 $\left.{ }^{\text {st }}\right)$ & $Y$ Axis $\left(2^{\text {nd }}\right)$ & $X$ Axis $\left(3^{\text {rd }}\right)$ \\
\hline $\begin{array}{l}\text { Pre-Vibration Crack } \\
\text { Pressure }\end{array}$ & 15.02 psid & 15.06 psid & 15.05 psid \\
\hline $\begin{array}{l}\text { Post-Vibration } \\
\text { Crack Pressure }\end{array}$ & $15.06 \mathrm{psid}$ & 15.05 psid & 15.13 psid \\
\hline $\begin{array}{l}\text { Air Leakage During } \\
\text { Vibration (Ibs) }\end{array}$ & $0.0043 \mathrm{lbs}$ & 0 & $6.8 \times 10^{-5} \mathrm{lbs}$ \\
\hline
\end{tabular}

Figure 5. Results of the Random Vibration Test on the Class I PPRA.

In comparing Figures 4 and 5, it can be seen that the Class I and Class III valves were very similar and consistent in their behavior and performance. The Class I valve leaked less air during vibration, in spite of its lower "crack" pressures. As with the Class III unit, air leaks of the size recorded could not be measured, and would not be noticed, on an actual spacecraft. And, as with the vibration test of the Class III unit, the nominal Orion and $+3 \mathrm{~dB}$ Protoflight vibration levels did not damage the mechanical function of the Class I valve, or affect its performance in any significant way. The observed differences in crack and reseat pressures, all on the order of $0.1 \mathrm{psi}$ or less, were not significant to the intended use of the valve on EFT-1.

These results confirmed that an existing Class I PPRA, borrowed from the ISS / MPLM inventory, would be suitable for use on the EFT-1 mission, resulting in a significant cost savings to the Orion Program.

\section{GROUND SUPPORT EQUIPMENT HEAT EXCHANGER (GSE HX)}

\section{Hardware Description}

The limited complement of avionics, power and data hardware on the EFT1 mission means that the EFT1 cooling requirements are relaxed compared to the crewed flight configuration, and so the ammonia boiler is the only component necessary to remove the heat generated by the powered equipment. However, in order to avoid unnecessary use of ammonia before launch, there is still a need for supplemental cooling on the launch pad. For the crewed flight configuration, the ATCS system utilizes a complicated heat exchanger that performs both the interface heat transfer function of transferring heat from the internal loop to the external loop, as well as providing cooling to the external loop via interaction with a ground support loop. As this new heat exchanger is complicated, and thus more expensive, a survey of "heritage" heat exchangers was carried out, to determine if any could be utilized on EFT-1 as a cost-saving measure. 
While several heat exchangers in the Shuttle fleet were potential candidates for providing ground support cooling, the Ground Support Equipment Heat Exchanger was ultimately chosen to perform this function on EFT1. Shown in Figure 6, the GSE Heat Exchanger is a liquid/liquid heat exchanger that was located in the aft bay of the Orbiter, where the vehicle's Freon 21 loop transferred heat generated while on the pad to the ground based R134a loop. It is a counterflow heat exchanger, with two separate loops on the ground side interacting with two Freon loops on the vehicle side. It is designed to remove 31.2 $\mathrm{kW}$. It has dimensions of 13.5 inches by 4.3 inches by 7.4 inches, and weighs $13.5 \mathrm{lbs}$.

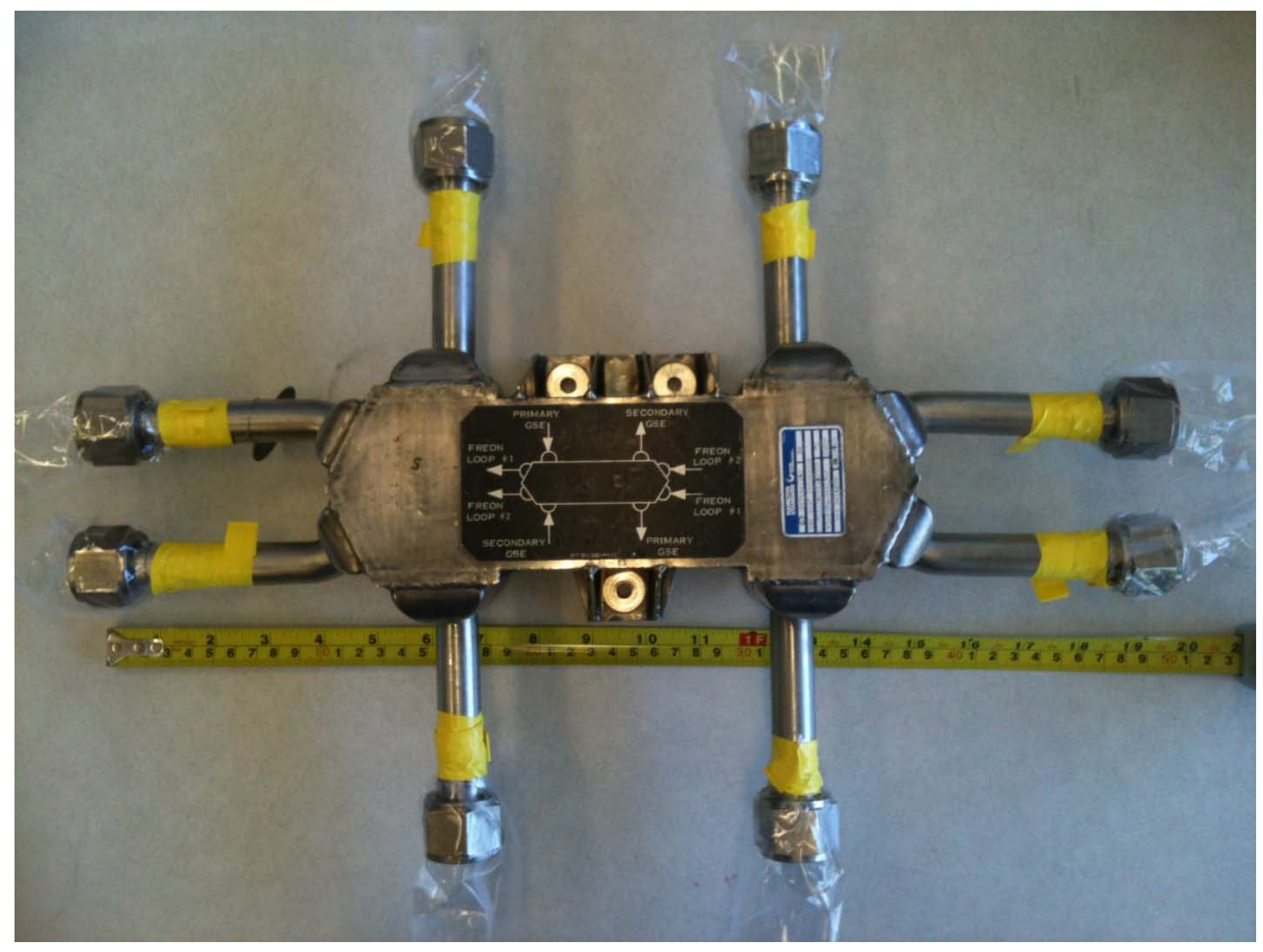

Figure 6. Qualification Shuttle Ground Support Heat Exchanger.

\section{Ground Support Cooling Requirements for Exploration Flight Test One}

As previously stated, the EFT1 mission will be a two orbit mission with a flight time of approximately 4.5 hours, plus an active post landing duration of 15 minutes to one hour. During the powered phases of the mission, including pre-launch operations on the pad, the ATCS picks up heat from electronic boxes located on 11 cold plates throughout the pressurized and unpressurized portions of the crew module. For the EFT1 mission, no cold plates are located in the service module. Including the heat generated by the coolant pumps and additional environmental heating, the coolant loops collect just under 900W on each of the two 50/50 propolyne glycol/water (PGW) loops. While this is much lower than the design point for the Shuttle GSE HX, it was determined that the difference in fluids between the two programs required a development test to show that the Shuttle hardware would be able to remove the heat load using a different fluid on the vehicle side.

\section{Orion Propolyne Glycol Testing}

In order to reduce any risk associated with using PGW instead of Freon on the vehicle side of the GSE heat exchanger, a development test was conducted at the Johnson Space Center in January 2011. Due to the hazardous nature of R134a, it was 
determined that using PGW on both sides of the heat exchanger would be a conservative test, because PGW is a less efficient heat transfer fluid than R134a. The test schematic and a picture of the test set up are shown in Figure 7. This simple test consisted of two PGW chiller carts, flow meters, pressure transducers and temperature sensors. The heat exchanger and tubing were covered with insulation to reduce heat transfer with the surrounding air.

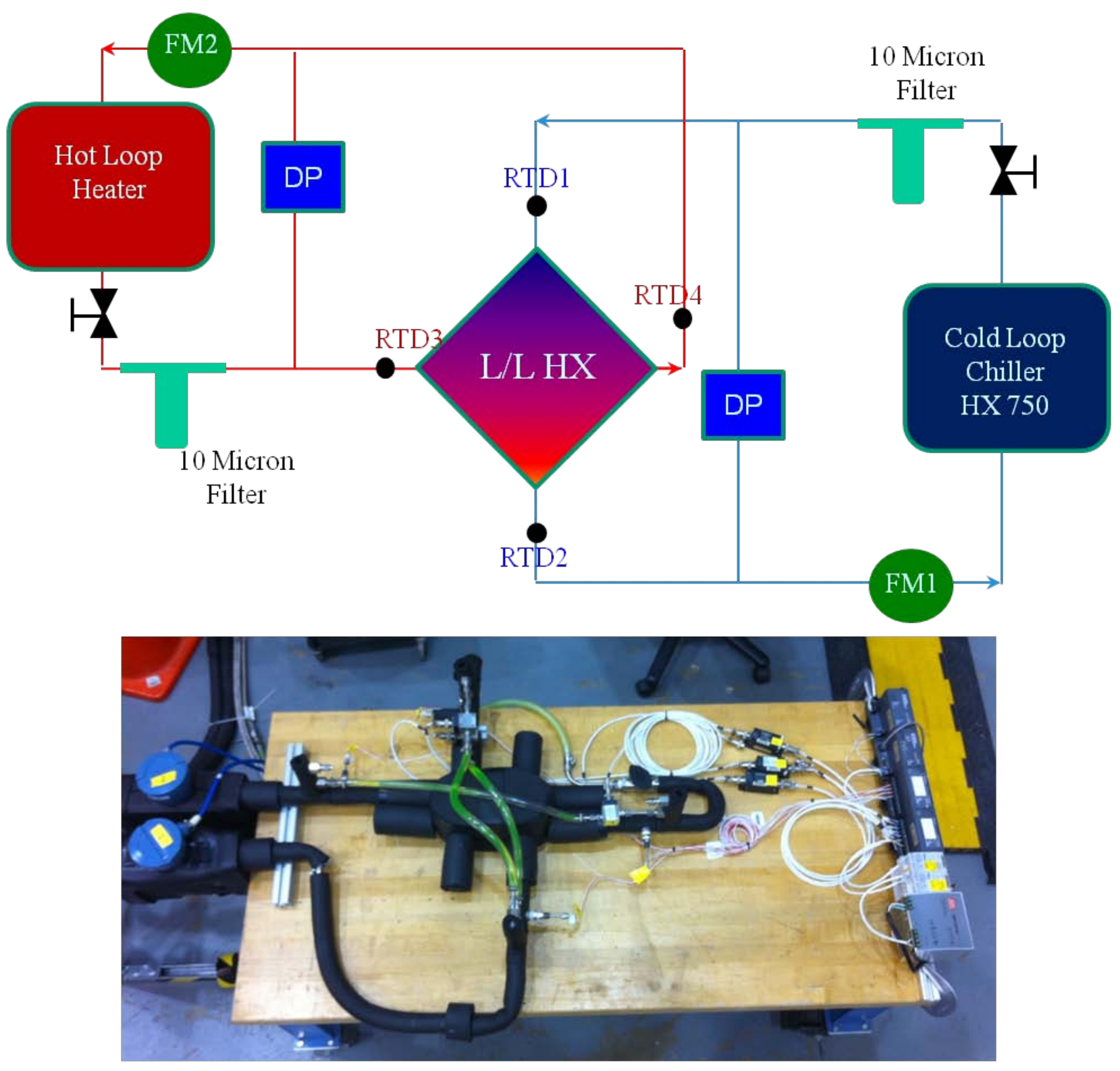

Figure 7. GSE HX Development Test Schematic and test setup.

To mimic conditions on the real vehicle, the hot (vehicle) loop was maintained at a flow rate of $235 \mathrm{lb} / \mathrm{hr}$ and a temperature entering the HX of 58 deg F (14.4 deg C). The cold (ground) loop utilized four different PGW flowrates, from 100 to 750 $\mathrm{lb} / \mathrm{hr}$, and two different inlet temperatures, $23 \operatorname{deg} \mathrm{F}$ and $0 \operatorname{deg} \mathrm{F}$ (-5 deg $\mathrm{C}$ and $-17.8 \mathrm{deg} \mathrm{C}$ ). The results for the 23 deg $\mathrm{F}$ inlet condition are shown in Figure 8, and results for the 0 deg $\mathrm{F}$ condition are shown in Figure 9. The results of this test show that the heat exchanger more than adequately covers the heat rejection range necessary for the EFT1 mission. While this data reduces the uncertainties of using the heritage hardware, during the spring of 2012 Lockheed Martin will conduct a second series of tests which will utilize the proper R134a in the ground loop. Lockheed's data will allow a complete performance 
map of the heat exchanger to be assembled, thereby permitting more accurate and detailed modeling and analysis of the EFT1 mission.

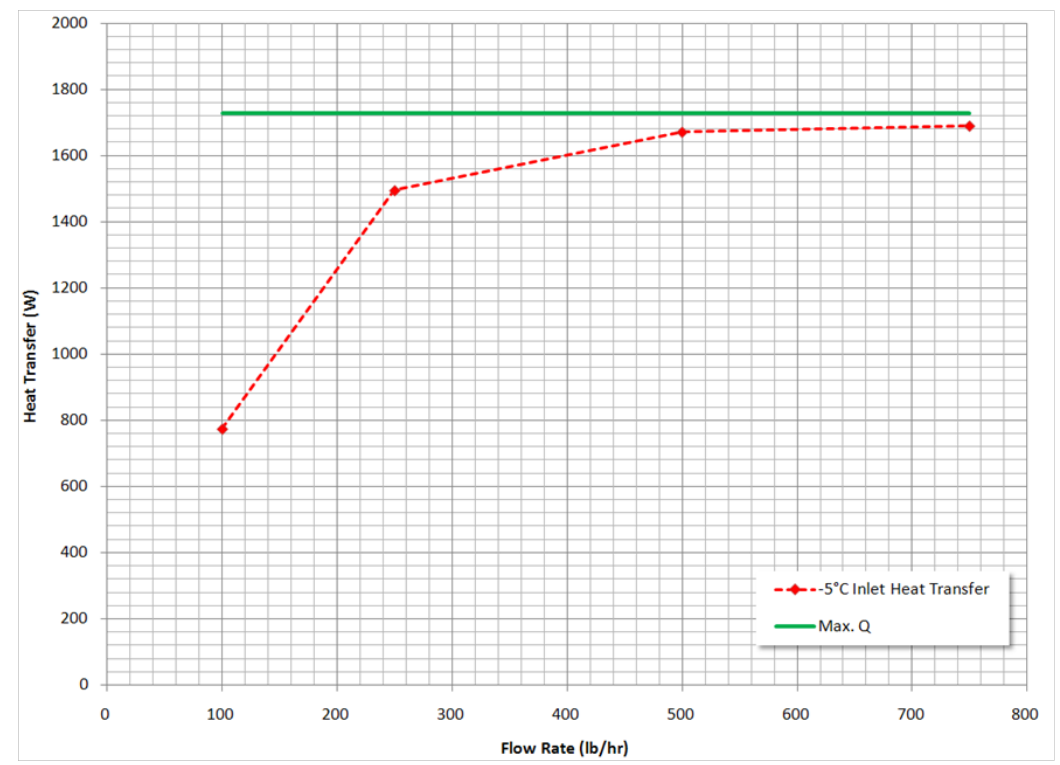

\begin{tabular}{|c|c|}
\hline \multicolumn{2}{|c|}{ Pressure Drop } \\
\hline $\begin{array}{c}\text { Flow Rate } \\
(\mathrm{lb} / \mathrm{hr})\end{array}$ & $\begin{array}{c}\text { Pressure } \\
(\text { psid })\end{array}$ \\
\hline 100 & 0.9 \\
\hline 250 & 2.4 \\
\hline 500 & 5.5 \\
\hline 750 & 8.9 \\
\hline
\end{tabular}

Figure 8. 23 Degree F Cold Side Inlet Temperature Results

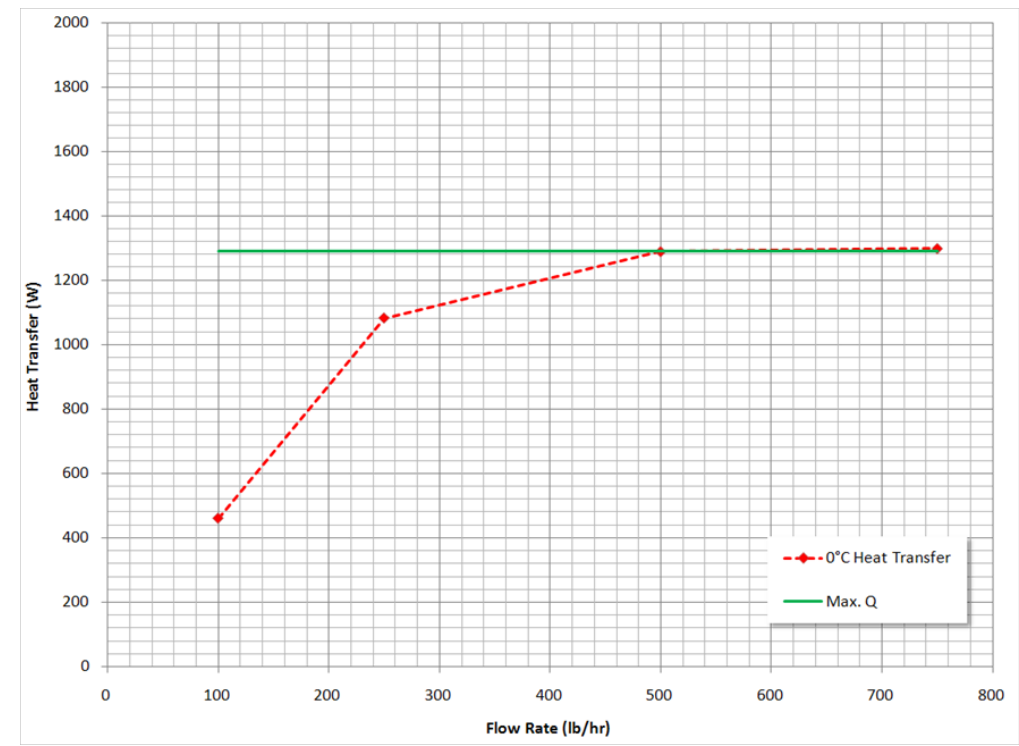

\begin{tabular}{|c|c|}
\hline \multicolumn{2}{|c|}{ Pressure Drop } \\
\hline $\begin{array}{c}\text { Flow Rate } \\
(\mathrm{lb} / \mathrm{hr})\end{array}$ & $\begin{array}{c}\text { Pressure } \\
\text { (psid) }\end{array}$ \\
\hline 100 & 0.6 \\
\hline 250 & 1.8 \\
\hline 500 & 4.4 \\
\hline 750 & 6.7 \\
\hline
\end{tabular}

Figure 9. 0 Degree F Cold Side Inlet Temperature Results

\section{Hardware Availability}

Both the NASA JSC and Lockheed Martin tests were performed on the qualification heat exchanger. In addition to this unit, there are two flight spares that NASA has transferred to Lockheed for possible use on the EFT1 and subsequent Orion missions. Neither of the flight spares has ever seen flight use, and therefore can be considered pristine. However, due to the location of the GSE HX in the service module of the spacecraft, they will be expended with the service module, and are thus one time only use. 


\section{CONCLUSIONS}

The possible use of heritage space flight hardware for the Orion EFT1 mission was evaluated, and it was determined that the MPLM PPRA valve and the Shuttle GSE HX were available resources that offered cost and schedule benefits, while still meeting EFT1 mission performance requirements. Although the use of heritage hardware does present unique challenges, particularly in the area of vibration testing, it is one avenue that will continue to be pursued in order to reduce the cost of future space flight missions. 